\title{
Sexual abuse against children with disabilities in the community
}

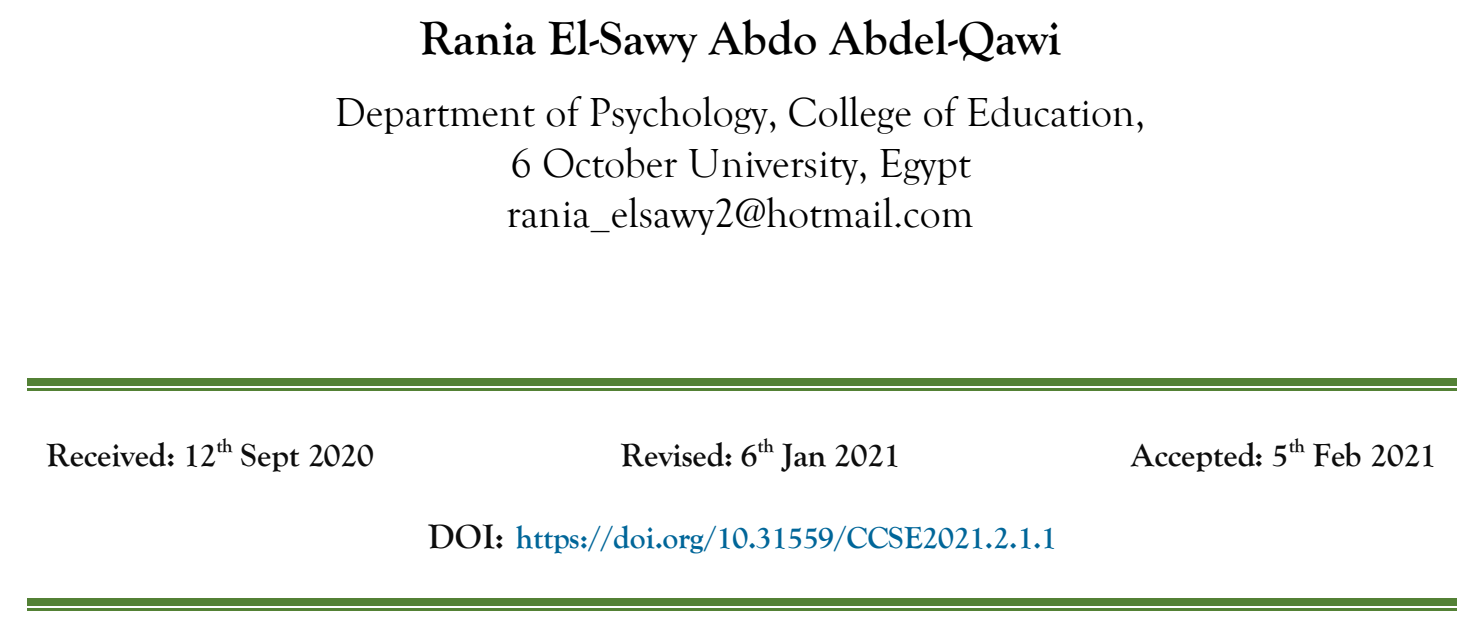




\title{
Sexual abuse against children with disabilities in the community
}

\author{
Rania El-Sawy Abdo Abdel-Qawi \\ Department of Psychology, College of Education, 6 October University, Egypt \\ rania_elsawy2@hotmail.com
}

Received: $12^{\text {th }}$ Sept 2020 Revised: $6^{\text {th }}$ Jan 2021 Accepted: $5^{\text {th }}$ Feb $2021 \quad$ DOI: https://doi.org/10.31559/CCSE2021.2.1.1

Abstract: The current study aimed to review the most prominent axes related to sexual abuse against children with disabilities in society, including1- Learn about the concept and forms of sexual abuse for people with disabilities.2- Recognizing the physical, psychological, and social effects of abuse.3- Responsible for exposing a child with disabilities to harassment or exploitation.4- The available treatment methods to reduce the consequences of the abuse if it develops into sexual assault.

5- Educating the family of people with disabilities about the possibility that their child will be exposed to sexual harassment.6-Adding the subject of sexual education as an effective means of preventing harassment against people with disabilities.

7-Educating the family, society and those working with people with disabilities about the correct scientific methods and concepts of sex education as a healthy and preventive means against harassment of all kinds.

8- Establishing proposed procedural mechanisms that help workers in the field of special education to know the most important preventive and awareness programs and to activate them in all educational stages.

Keywords: sexual abuse; people with disabilities.

*Corresponding author

Rania El-Sawy Abdo Abdel-Qawi

Department of Psychology, College of Education, 6 October University, Egypt

E-mail: rania_elsawy2@hotmail.com 
International Journal of Childhood, Counselling, \& Special Education (CCSE), Volume2, Issue: 1, March: 2021, pp.1-15

\section{Introduction}

Considering the orientation of international and national conventions towards the protection of children in general and their protection from forms of sexual exploitation in particular, the issue of sexual abuse has become one of the most prominent social issues covered by laws and regulations, for which seminars and conferences are held and adopted by studies and research, and within this vision the role and responsibility of the family towards that protection has been emphasized. Where the family plays an important role in the psychological, social, and intellectual growth and development of the child, Accordingly, the concern for the problem of people with disabilities came to become a global concern because of the negative effects of this phenomenon on the individual level (the disabled child) and on the societal level as well. The organization in 1981 in the International Year of the Disabled (Al-Badayna, 1996, Association of Special Groups and Handicapped Organizations, 1998, McEachern, Adriana G. 2012, GilLlario, etc, 2018)

The problem is as a hidden and widespread phenomenon at the same time, but it is still kept secret, and this explains the scarcity of studies that dealt with it in our Arab world, in addition to the continuous increase in the percentage of people with disabilities, which forces governments and organizations to legislate laws that guarantee their rights, as people with disabilities, as indicated by both :(Badr, 2001, al-Tanbari, 2003, Abd al-Latif,
2007, Abu Bakr, 2010, Darwish, 2012, Morsi, 2013) they are more exposed to violence, exploitation and abuse than others, as disability constitutes an attractive source of their exposure to this type of practices. (Sobsey \& Varnhagen, 1989, Gomaa, 2009, McEachern, Adriana G. 2012, Mansour, 2014) indicated that most persons with disabilities, regardless of disability category, are subjected to sexual abuse. Mansour, 2013, 2014) that victims with mental deficiencies are more likely to be exposed to sexual abuse, and from here I tried to emphasize the need for society to understand the problem and to work on concerted various efforts to reduce its negative effects on the disabled child or his family, so she focused on a group of the following main axes:

1. Identify the concept of sexual abuse and its forms for people with disabilities.

2. Identify the effects of physical, psychological, and social abuse.

3. Who is responsible for exposing a child with a disability to harassment or exploitation?

4. What treatment methods are available to reduce the consequences of the abuse if it develops into sexual assault?

5. How aware is the family of persons with disabilities about the possibility of their child experiencing sexual harassment?

6. Is adding sex education as a preventive measure against harassment of people with disabilities effective? 
7. Raising awareness of the family, society and those working with people with disabilities about the correct scientific methods and concepts of sex education as a healthy and preventive means against harassment of all kinds.

8. Establishing proposed procedural mechanisms that help workers in the field of special education to know the most important preventive and awareness programs and to activate them in all educational stages.

First of all, we must point out that there are many classifications and designations for people with disabilities according to subjective, medical, educational and social criteria and according to their appearance in different age stages and according to the nature of the causes and on the basis of the external appearance of the senses as indicated by: (Al-Zoabi, 2003: 103-315, Goodyear-Brown (Paris, 2012), and scholars have unanimously classified persons with disabilities as follows: (mental disability - hearing disability visual impairment - movement (physical) disability learning difficulties - speech language disorders - emotional disorders (autism, hyperactivity associated with attention deficit) (AlEssawi, 1997: 155-165, World Health Organization, 2013)

The World Health Organization also defines persons with disabilities as follows: "Disability is a term that covers disability, restrictions on activity, and restrictions on participation. Disability is a problem in the function or structure of the body, and limiting activity is the difficulty that an individual faces in carrying out a task or work, while Restriction of participation is the problem that the individual suffers from in participating in life situations, and therefore disability is a complex phenomenon, which reflects the interaction between the features of a person's body and the features of the society in which he or she lives. (World Health Organization, 2013)

http://www.arabvolunteering.org/corner/av t2646.html

Therefore, we will address the main axes as follows:

\section{Identify the concept of sexual abuse and its forms for people with disabilities.}

He agreed with (Badr, 2001, ElSayed, 2005, Sadiq, 2007, Higgins, M. and Swain, J. 2010, Gil-Llario, etc, 2018) in their definition of sexual abuse which refers to the use of the child to satisfy sexual desires. For an adult or teenager, or among minors, the age difference between them is over five years, and harassment includes exposing the child to any sexual activity or behavior such as touching him or making him meet the sexual harasser, and other forms of sexual abuse against the child: sexual intercourse, child prostitution and sexual exploitation of the child through pictures Pornography and porn sites.

Sexual abuse of people with disabilities, as indicated by: (Al-Talhi, 2000, Abu Halawa, 2004, GoodyearBrown, Paris, 2012) is one of the most severe and cruel crimes in the field of 
International Journal of Childhood, Counselling, \& Special Education (CCSE), Volume2, Issue: 1, March: 2021, pp.1-15

violence against children, and this phenomenon can be rightly described (with a conspiracy of silence and secrecy) that It imposes itself from the scarcity of talking about it, to the secrecy of both the victim and the perpetrator, Likewise, in the case of the family knowing, for many varied reasons related to impotence, fear of shame, staining the reputation, or preserving the psychological health of the victim, and the sexual exploitation of a child's body is defined as sexual intercourse between a child and an adult in order to satisfy the sexual desires of the latter, using force and control over the former, The sexual exploitation or harassment of the child is determined by exposing his genitals, removing clothes from him with the aim of special physical touching or caressing him, rape or indecent assault, exposing him to pornographic pictures or films or forcing him to utter obscene words.

\section{Identify the effects of physical,} psychological, and social abuse.

Exposure to sexual abuse results in severe psychological, physical, and behavioral effects that are harmful or dangerous. Trust suffers from severe damage affecting most of their psychological structure compared to people who are subjected to sexual abuse late in their lives and a few times in a non-aggressive manner at the hands of people unknown to them.

There are many manifestations of the effects of physical, psychological, and social abuse, as indicated by: (Sobsey,1994، Lalor, K. ,2004 ،Gilson,
S. F., etc.,2001، Calitz, F.J.W. ,2011، Myaka, L.D. ,2012، Phasha T.N. \& Nyokangi, D. ,2012)

\section{- Physical signs or indications.}

(A) The presence of blue bruises or bruises in the sexual organs.

(B) Discomfort, tension, or general sexual irritability.

(C) Sexually transmitted diseases.

(D) The presence of signs of physical abuse.

(E) The presence of holes or tears in the clothes or the loss or absence of clothes.

(F) Unexplained or illegitimate pregnancy.

- Signs or behavioral indicators.
(A) Depression and general distress.
(B) Misuse of drugs or drug giving.
(C) Social withdrawal or withdrawal behavior.

(D) Unnatural or abnormal attachment or attachment to a specific person or persons.

(E) Avoiding being in certain situations.

(F) Sudden seizures.

(G) Avoiding interaction with and fear of specific people.

(H) Severe and prolonged crying spells.

(I) Conversion or recidivism in the sense of engaging in behavioral behaviors not appropriate for the victim's progressive stage.

(K) Sleep disturbances.

(L) To declare, disclose, or talk about an incident or facts of abuse.

(M) Low or low self-esteem.

(N) Rebellion, disobedience, transgression, or stubbornness. 
International Journal of Childhood, Counselling, \& Special Education (CCSE), Volume2, Issue: 1, March: 2021, pp.1-15

(U) Eating disorders.

(O) Refusal of tests or medical examinations.

(V) Self-harm behavior.

(Y) Headache.

(R) Learning difficulty.

(Z) Reprehensible or objectionable sexual behavior.

- Situational or situational signs or indicators.

(A) Breeder or caregiver abuse of alcohol or drug or drug misuse.

(B) Despicable or degrading attitudes and the adoption of such trends by those in charge of raising and caring for children.

(V) Irritability or sexual excitement that is exaggerated, inappropriate or deplored.

(W) Isolation of the social unit.

(C) Exposure to other forms of abuse.

(H) Exposure to abuse in previous life stages.

(X) Searching for individual communication with children.

(D) Preference for dealing with children.

(Y) Being with other caregivers and educators, i.e., the mother's surrogate or the father's surrogate.

(T) Not addressing facts or events of abuse that were previously exposed.

(G) Habitual pornography or immorality and encouragement for it.

3. Who is responsible for exposing a child with disabilities to harassment or exploitation?

Sexual violence against children is a gross violation of children's rights. Yet it is also a global reality in all countries and among all social groups. It takes the form of sexual assault, rape, sexual harassment, prostitution, or pornography.

As part of UNICEF's commitment to the Convention on the Rights of the Child and the Rio de Janeiro Declaration and the call to action to prevent and end sexual exploitation of children and young people, UNICEF works to prevent and respond to sexual violence by engaging various government sectors - justice, social welfare, education, and health - as well as legislators, civil society, and community leaders. Religious groups, the private sector, the media, families, and children themselves.

That is why UNICEF supports governments in strengthening child protection systems, at the national and local levels - including laws, policies and regulations and providing comprehensive services for child victims. UNICEF also works with communities and the public to raise awareness of the problem and address attitudes, norms and practices that are harmful to children. (https://www.unicef.org/ar)

Therefore, the state has a responsibility to protect persons with disabilities from torture. Cruel, cruel, inhuman, or degrading treatment. And she should do that. Using means such as legislation, procedures, and international agreements and commitment to implement them, and any efforts and programs undertaken by civil society institutions and international institutions must be 
International Journal of Childhood, Counselling, \& Special Education (CCSE), Volume2, Issue: 1, March: 2021, pp.1-15

within the context of this responsibility and support it, not a substitute for it.

\section{What treatment methods are available to reduce the consequences of the abuse if it develops into sexual assault?}

When a person is sexually assaulted, he has a desire to separate from the event, take it away from his memory and try to forget it completely. Numerous studies indicate that this effort often fails, adding to feelings of anxiety and isolation among victims of sexual assault. Therefore, the authorities, whatever they are, ask victims of sexual assault to go to various aid centers and support services, which can contribute to dealing with this abuse. (Lalor K, McElvaney R.,2010)

These centers invite victims of sexual assault to go to them as soon as possible after the occurrence of the event; so that their treatment is effective and that, they do not accumulate various problems that need treatment. These centers offer a wide range of support and assistance programs for victims of sexual assault, so that they do not have to face the event on their own. If they feel difficult to reveal themselves, they can use emergency lines that allow them to remain anonymous.

These centers assist victims of sexual assault in a few ways, as indicated by) :Jonzon E, Lindblad F., 2006 ، McClure F, et al., 2008 ،Gillies D, Taylor F, Gray C, et al., 2012)

First: If the victim is a minor, they accompany her to the police, where with their help - she must file a complaint, and in cases where the victim wants to file a complaint but does not know how to do so.

Second: The center provides medical assistance if needed. It also collects information about the victim, so that he can treat it now and in the future. The treatment provided by the center depends on the victim's generation, the support systems available to him, and the nature of the harm, the difficulties they may face, and other matters.

For example, if it is about a onetime, close sexual assault, and there is a strong support system such as family and friends, the center provides shortterm help. This help can be helpful in the intended coping with symptoms that accompany sexual assault, such as post-traumatic stress disorder, nightmares, flashbacks, and fear. There are several methods of short-term treatment, such as sustained exposure, cognitive behavioral therapy, and the EMDR method.

These methods focus on posttraumatic stress symptoms following the event, sensory analysis of it, acquiring self-soothing skills, dealing with guilt, and a correct understanding of sexuality. As for cases where the assault occurred long before heading to the center, treatment is also carried out for the impact of the event on the victim's personal relationships.

After the sexual assault has occurred, other family members are also in a state of shock. In this case, going to family counseling can be an important factor in dealing with this event. It is important to realize that not only the 
International Journal of Childhood, Counselling, \& Special Education (CCSE), Volume2, Issue: 1, March: 2021, pp.1-15

victim faces the assault, but also her family members face it from the moment they know about it.

5. How aware is the family of persons with disabilities about the possibility of their child experiencing sexual harassment?

There is no doubt that there is an important role in the awareness of the family of people with disabilities about the possibility of their child experiencing sexual harassment, so there are some things as indicated by each of: (Young, A., et al., 2009, Stalker, K., et al., 2010, Stalker, K. and McArthur, K., 2012, Scottish Government, 2014) Which should be made aware of them so that they can train their children on it to protect them from sexual abuse, including:

- Awareness from an early age and frankly away from vulgarity while ensuring safe family relationships.

- Integration with strangers is accompanied by a family member or trusted person, taking gifts from them under supervision, and dealing with them with caution and attention in the event of strange situations or behavior.

- Unsure of strangers just because they know their parents, or by calling them by name and accompanying them on their own.

- Ensure that the child or person with disabilities can seek help by multiple means in the event of harassment.

- Providing all the child's needs so that he is not exposed to physical temptation.
- Considering the age stage that the child and the person with disabilities are going through and giving the appropriate information for each stage with a different method of clarification between adults and children.

- Stay away, as much as possible, from placing children in one bed.

- Follow-up and monitoring during periods of children leaving each other.

- Differentiate between adolescents and children in playing games for fear of exploitation, and for the child to realize that he is vulnerable to abuse from relatives.

- Considering the privacy of parents in practicing sexual relations and not giving children an opportunity to snoop or hear voices.

- Stay away from delving into topics that contain excitement and suspense.

- Parents refrain from touching children's genitals with the aim of making fun, and the child realizes that his body belongs to him and that no one may touch it, especially in sensitive areas.

How do we encourage them to tell (frankness)?

Parents should build bridges of trust and safety between them and their children with disabilities to encourage them to be frank with them when they are exposed to any situation in which they are sexually abused, and there are some methods and means that parents can follow to achieve this, including:

- Giving children sufficient affection and affection, and instilling 
International Journal of Childhood, Counselling, \& Special Education (CCSE), Volume2, Issue: 1, March: 2021, pp.1-15

confidence in the relationship between parents and children.

- Staying away from instilling fear in children and encouraging them to be frank and honest.

- Cultivating the values of the importance of the family، its solidarity, and its function to protect its members.

- The mother's proximity to the girl, helping her to solve her problems, and talking with her on various topics, including sexual harassment.

- Close the father to his son and encourage him to be frank and honest.

- Continuing to give children different models through stories, narration, and interpretation of events, especially regarding the values of honor and chastity and the social problems related to them.

6. Is adding sex education material as a preventive measure against harassment of persons with disabilities effective?

(Badr, 2001, Abdo, 2005, Makhzoumi, 2007, Rabi`, 2009, Darwish, 2012) indicated that sex education can be described as gender education to include all sexual aspects such as: family planning, reproduction (fertilization, pregnancy, fetal development) Until birth) in addition to all aspects of personal sex, which include: physical view, sexual orientation, orgasm, values, decisionmaking, communication, dating, relationships, sexual diseases, methods of avoiding them, and birth control methods.

Sex education can be learned informally, such as when someone receives information through conversations with parents, a friend, a cleric, or through the media.

As for formal sex education, it is educational programs designed for schools, and the most important motives for interest in sex education came from the spread of AIDS, which has prompted many governments and schools to spread sexual awareness to limit its spread.

7. Educating the family, society and those working with people with disabilities about the correct scientific methods and concepts of sex education as a healthy and preventive means against harassment of all kinds.

(Alriksson-Schmidt, AI, et al., 2010, Talhi, 2010, Baladerian, NJ, et al., 2013, Kok, G., \& Akyuz, A., 2015, McDaniels, B., \& Fleming, A., 2016) indicated that there are many agencies responsible for protecting children with special needs from sexual abuse, including:

First: at the community level.

1. Focusing on encouraging programs and initiatives that limit the phenomenon of violence and exploitation. Among these programs and initiatives are the inclusion of persons with disabilities in programs for protection from violence and exploitation provided to all members of society, and the 
International Journal of Childhood, Counselling, \& Special Education (CCSE), Volume2, Issue: 1, March: 2021, pp.1-15

involvement of persons with disabilities in specialized treatment programs for victims of violence and exploitation.

2. Increasing awareness and focusing on awareness campaigns on issues of violence and exploitation of persons with disabilities and introducing organizations and institutions that are interested in these issues and their role in protecting persons with disabilities.

3. Emphasizing that governmental institutions and civil society organizations do everything necessary to follow up issues of violence and sexual exploitation to limit their spread.

4. Focusing on training government cadres, such as employing ministries and security agencies, on methods of detecting cases of violence and sexual exploitation and providing them with appropriate training courses.

Second: Working with persons with disabilities.

1. Those working with persons with disabilities must be aware of the danger of taking any act that leads to violence and exploitation.

2. The necessity of training workers with persons with disabilities on how to uncover and document issues of violence and exploitation, and the preliminary examinations that can be performed to uncover these practices.

3. Violence against persons with disabilities in care and permanent residence institutions should motivate the concerned authorities to follow up on these institutions.

\section{Third: At the family level.}

1. You should be subject to counseling and awareness programs that address how to deal with a disabled person.

2. Immediately report any case of violence or exploitation that the disabled person is exposed to, and not conceal this case.

3. Holding meetings and lectures to educate parents of persons with disabilities about issues of violence and exploitation.

8. Establishing proposed procedural mechanisms that help workers in the field of special education to know the most important preventive and awareness programs and to activate them in all educational stages.

It does not provide people with developmental disabilities with victims of sexual abuse the way they face or talk about traumatic experiences related to sexual abuse even while undergoing various psychotherapy programs.

A set of training techniques or procedures can teach victims of sexual abuse with disabilities:

- Self-insurance or self-defense skills.

- Skills of maintaining a healthy body.

- Skills for reporting an incident or incidents of abuse.

Social service workers, especially when dealing with people with developmental disabilities, must understand the nature of the disability in general and the psychological and 
International Journal of Childhood, Counselling, \& Special Education (CCSE), Volume2, Issue: 1, March: 2021, pp.1-15

behavioral characteristics of the disabled, and acknowledge in their conviction that victims of sexual abuse with developmental disabilities can benefit from methods or types of counseling and psychotherapy

Different.

Prevention methods for people with special needs according to their age:

(Park J, Faulkner J, Schaller M., 2003, Makhzoumi, 2007, Casteel C, 2008, Plummer SB, Findley P., 2012) referred to prevention methods for people with special needs according to their age as follows:

The breastfed child: to be careful with his nakedness and not leave him for anyone until he changes his clothes or protect him, and not to get him used to feeling the places of his private parts, just as we do not leave him at home alone with the house cleaner.

If the girl reaches the age of 6 : she does not go out of the house alone in the afternoon and evening periods, she is understood that no one tries to feel her in the places of her private parts, because this is a defect, and this is an area that no one will see, if she takes off her clothes, then take it off after making sure that the room door is closed. Never take off her clothes outside the house, whatever the reasons, never let her go out with the driver alone, never play with her cousins or her older cousins on her own, try to get her used to wearing long underwear (if she wears a dress), In addition to teaching her proper sitting method, such as not sitting with her leg open, and her clothes high, never entering the driver's or server's room, developing her self-censorship by training her to change television stations if immoral footage appears, even if she is alone, start the class in sleep About her young sibling.

If the child has reached the age of $6:$ he does not go out of the house alone in the afternoon and evening periods, accustom him to sleep on the right side in accordance with the Sunnah of the Prophet, because sleeping on his face leads to frequent itching of his genitals, it is understood that no one tries to touch him in places of his private parts. Begin to teach him permission before entering the mother and father at noon, dinner and dawn times, if he takes off his clothes, he makes sure that there is no one he can see, develops selfcensorship in him by training him to change television stations if footage appears offensive to morality, start the separation by sleeping about his sister's girls.

If the girl turns 10 years old: her mother explains to her the meaning of puberty and menstruation, her mother talks with her about the meaning of sexual assault and gives her stories on this topic, explaining the real reasons why her father forbids her the following: (Going out with the driver alone - playing with the cousins and maternal uncles Older adults alone entering places where male workers, dyers, servants, and cooks are present), raising the girl to modesty and a halal view, and changing television stations if immoral footage appears, or an indecent woman appears, starting to train her to refrain from wearing short and naked women at home, especially 
International Journal of Childhood, Counselling, \& Special Education (CCSE), Volume2, Issue: 1, March: 2021, pp.1-15

In front of her young siblings and her father, the need to stay away from girls in school who repeatedly try to touch, hold hands, or cuddle.

If the boy has reached the age of 10: his father explains to him the meaning of puberty + wet dreams, his father talks with him about the meaning of sexual assault, and gives him stories on this topic, explaining to him the importance of being careful in playing with his schoolmates and the need to pay attention to the following movements that come from older colleagues If repeated: (kissing - holding the hand and feeling it - placing a hand in the hair - physical attachment or hugging - praise for the beauty of the figure and the body), education on modesty and a halal view, and changing television stations if an immodest woman appears, or footage out of morals.

If the signs of puberty begin to appear on the girl: her mother explains to her the way the fetus is formed, and that the only way in Islam for it is marriage only, she explains to her the importance of wearing the hijab, and the reasons for which it came to prohibit going out without a hijab, her mother explains to her the prohibition of seclusion with a foreign person in practice All the children of her maternal aunts and aunts enter into this with an explanation of the meaning of seclusion that is forbidden according to Sharia, and her mother explains to her the method of washing and purity, and explains to her the importance of her distance from girls who distribute sex films or phone numbers of young men, explaining the characteristics of a
Muslim girl of high morals by not talking to any young man She doesn't know him, and he's trying to get to know her.

If the signs of puberty begin to appear on the boy: his father explains to him the way the fetus is formed, and that the only way in Islam for him is marriage only, he explains to him the importance of turning a blind eye, explaining to him that the Sharia forbidding the isolation of any girl, talks to him about the need to distance him from young men who promote films Sex and prompts to talk to girls.

\section{References}

Abdo, Samar. (2005). Violence and abuse of children. Al-Shorouk Publishing House, Beirut, Lebanon.

Abu Halawa, Muhammad Saeed AbdulGawad. (2004). Sex education for children and adolescents with special needs. Faculty of Education in Damanhour, Alexandria University, within the activities of the training course to qualify workers in the field of special education, supervised by: The Life for All Association for the Care of People with Special Needs, Egypt.

Al-Essawi, Abdul-Rahman. (1997). Psychology of physical and mental disability, with treatment and rehabilitation methods. Encyclopedia of Modern Psychology Books Series Dar Al-Ratib - Beirut - Lebanon.

Al-Tanbari, Faten Abdel-Rahman. (2003). Sexual harassment and its impact on children. Institute of Higher Studies for Childhood, Ain Shams University, Cairo, Egypt. 
International Journal of Childhood, Counselling, \& Special Education (CCSE), Volume2, Issue: 1, March: 2021, pp.1-15

Al-Zoubi, Ahmed. (2003). Special Education for the Gifted and the Disabled, and Ways to Care and Guide them. Zahran House, Amman, Jordan. Badayneh, Diab. (1996). Social stigma and disability, Mu'ta Research and Studies. Series (A) of the Journal of Social Sciences and Humanities, 11(3), Deanship of Scientific Research and Postgraduate Studies, United Arab Emirates University, Emirates.

Badr, Adel. (2001). Child Sexual and Physical Exploitation. Fourth Annual Conference, National Center for Social and Criminal Research, Cairo, Egypt.

Baladerian, N. J., Coleman, T. F., \& Stream, J. (2013). Abuse of people with disabilities: Victims and their families speak out. A report on the 2012 national survey on abuse and people with disabilities. Retrieved fromhttp://disabilityabuse.com/survey/survey-report.pdf. Calitz, F.J.W. (2011). Psycho-legal challenges facing the mentally restarted rape victim. South African Journal of $\begin{array}{lll}\text { Psychology, } & 17 \quad \text { (3), 66-72, }\end{array}$ https://doi.org/10.4102/sajpsychiatry.v17 i3.280.

Casteel C, Martin S, Smith J, Gurka K, Kupper L. (2008). National study of physical and sexual assault among women with disabilities. In Prev.;14 (2), $87-90$, https://doi.org/10.1136/ip.2007.016451. Disabled Children from Abuse and Neglect Alriksson-Schmidt, A. I., Armour, B. S., \& Thibadeau, J. K. (2010). Are adolescent girls with a physical disability at increased risk for sexual violence? Journal of School Health,
80(7), 361-367, doi:10.1111/j.17461561.2010.00514. x.

Gillies D, Taylor F, Gray C, et al. (2012). Psychological therapies for the treatment of post-traumatic stress disorder in children and adolescents. Cochrane Database Syst Rev. (12), CD006726,

https://doi.org/10.1002/14651858.cd00 6726.pub2.

Gil-Llario, $\mathrm{M}^{\mathrm{a}}$ Dolores; MorellMengual, Vicente; Díaz-Rodríguez, Irene; Ballester-Arnal, Rafael (2018). Prevalence and sequelae of selfreported and other-reported sexual abuse in adults with intellectual disability. Journal of Intellectual Disability Research, 63(2), 138-148, doi:10.1111/jir.12555.

Gilson, S. F., Cramer, E. P., \& DePoy, E. (2001). Redefining abuse of women with disabilities: A paradox of limitation and expansion. Affilia, 16 (2), 220-235,

https://doi.org/10.1177/0886109012209 4235.

Goodyear-Brown, Paris (2012). Handbook of child sexual abuse: Identification, assessment, and treatment. New Jersey: John Wiley $\mathcal{E}$ Sons Inc. p. 8. ISBN 978-1-118-08292.

Hassan, Lana. (2012). The extent to which mothers of primary school children are aware of the symptoms and mechanisms of protecting their children from sexual harassment and abuse, an exploratory study on a sample of mothers of primary school children in the city of Riyadh. Journal of the Faculty of Social Work, issue thirty-second, part ten, Helwan University, Cairo, Egypt. 
International Journal of Childhood, Counselling, \& Special Education (CCSE), Volume2, Issue: 1, March: 2021, pp.1-15

Higgins, M. and Swain, J. (2010). Disability and child sexual abuse: Lessons from survivors' narratives for effective protection, prevention, and treatment. London.

Jessica Kingsley World Health Organization (2013). How to use the ICF. A Practical Manual for using the International Classification of Functioning, Disability and Health (ICF). Exposure draft for comment. Geneva: WHO.

Hussein, Azhar. (2010). The effectiveness of a computer program using multimedia in educating children about sexual harassment, Institute of Higher Studies for Childhood, Ain Shams University, Cairo, Egypt.

Jonzon E, Lindblad F. (2006). Risk factors and protective factors in relation to subjective health among adult female victims of child sexual abuse. Child Abuse Negl., 30,127-43.

Khaliqi, Hind. (1990). The relationship between physical and sexual abuse of the child and some demographic variables related to abusive families, unpublished master's thesis, University of Jordan, Amman, Jordan .

Kok, G., \& Akyuz, A. (2015). Evaluation of effectiveness of parent health education about the sexual developments of adolescents with intellectual disabilities. Sexuality and Disability, 33, 157-174, doi:10.1007/s11195-015-9400-1.

Lalor K, McElvaney R. (2010). Child sexual abuse, links to later sexual exploitation/high-risk sexual behavior, and prevention/treatment programs. Trauma Violence Abuse,11(4),159-77, https://doi.org/10.1177/1524838010378 299.

Lalor, K. (2004). Child sexual abuse in Sub-Saharan Africa: A literature review. Child Abuse and Neglect, 28(4), 439-460, https://doi.org/10.1016/j.chiabu.2003.07 .005 .

Man Arrested And Charged In Sexual Assault Of Developmentally Disabled Man (2014).WBal ( NEWSRDIO . Thursday-September 25.

McClure F, Chavez D, Agars M, et al. (2008). Resilience in sexually abused women: risk and protective factors. $J$ Fam Psychol., 23(2), 81-88, https://doi.org/10.1007/s10896-007-

9129-4.

McDaniels, B., \& Fleming, A. (2016). Sexuality education and intellectual disability: Time to address the challenge. Sexuality and Disability, 34(2), 215-225. doi:10.1007/s11195-016-9427$\mathrm{y}$.

McEachern, Adriana G. (2012). Sexual Abuse of Individuals with Disabilities: Prevention Strategies for Clinical Practice. Journal of Child Sexual Abuse, 21 (4): 386-398, doi:10.1080/10538712.2012.675425. PMID 22809045.

Mr., Iman. (2005). Child sexual harassment. Al-Qalam Publishing House, Beirut, Lebanon.

Myaka, L.D. (2012). Understandings of sexual abuse involving teenagers with intellectual disability in a rural area of KwaZulu-Natal. Unpublished M.Ed. thesis. University of South Africa. Pretoria. Park J, Faulkner J, Schaller M. (2003). Evolved disease-avoidance processes and contemporary anti-social behavior: prejudicial attitudes and avoidance of 
International Journal of Childhood, Counselling, \& Special Education (CCSE), Volume2, Issue: 1, March: 2021, pp.1-15

people with physical disabilities. J Nonverbal Behave., 27(2), 65-87.

Phasha T.N. \& Nyokangi, D. (2012). School-based sexual violence amongst female learners with mild intellectual disability in South Africa. Violence against Women Journal, 18 (3), 309-321, https://doi.org/10.1177/1077801212444 578.

Plummer SB, Findley P. (2012). Women with disabilities' experience with physical and sexual abuse review of the literature and implications for the field. Trauma Violence Abuse., 13(1),1529,

https://doi.org/10.1177/1524838011426 014.

Sadiq, Fathia Rushdie. (2007). Child rape, a crime on the rise, Arab Book House, Cairo, Egypt .

Scottish Government (2014). National Guidance for Child Protection in Scotland. Additional Notes for Practitioners: Protecting.

Sobsey, D. \& Doe, T. (1991). Patterns of sexual abuse and assault. Sexuality and Disability, 9 (3), 243-259, https://doi.org/10.1007/bf01102395.

Sobsey, D. \& Varnhagen, C. (1989). Sexual abuse and exploitation of people with disabilities: Toward prevention and treatment. In M. Csapo and $L$. Gougen (Eds.) Special Education across Canada (pp.199-218). Vancouver: Vancouver Centre for Human Developmental and Research.

Sobsey, D. (1994). Violence and abuse in the lives of people with disabilities: The end of silent acceptance? Baltimore: Paul H. Brookes Publishing Co.

Stalker, K. and McArthur, K. (2012). Child abuse, child protection and disabled children: A review of recent research. Child Abuse Review, 21(1), 2440, https://doi.org/10.1002/car.1154.

Stalker, K., Green Lister, P., Lerpiniere, J. \& McArthur, K. (2010). Child Protection and the Needs and Rights of Disabled Children and Young People: A Scoping Study. Abridged report. University of Strathclyde. http://strathprints.strath.ac.uk/27036/1/ child protection abridged report.pdf.

Tower, C. (1989). Understanding child abuse and neglect. Boston: Allyn and Bacon.

Union of Bodies for Special Groups and the Disabled. (1998). People with special needs and the twenty-first century in the Arab world. Research, studies and recommendations of the 7th conference - December 1998, Cairo, Egypt.

Young, A., Hunt, R., Oram, R. \& Smith, C. (2009). The Impact of Integrated Children's Services on the Scope, Delivery and Quality of Social Care Services for Deaf Children and Their Families. London: National Deaf Children's Society. www.ndcs.org.uk/document. $\mathrm{rm}$ ?id=4668.

\section{Internet sites:}

Al-Talhi, Adel Abu Bakr. (2010). Violence against children with disabilities (sexual exploitation), Aman website: Solidarity Institute for Women International / Jordan.

http://www.nesasy.org/-intro-

99/8634-q-q6806

Abdel-Latif, Samah Mohamed Lotfy. (2007). Sexual problems of a mentally handicapped son, an article in the Gulf Association for Disability. 
International Journal of Childhood, Counselling, \& Special Education (CCSE), Volume2, Issue: 1, March: 2021, pp.1-15

http://www.gulfkids.com/ar/index.ph p?action=show $\_$art\& $A r t C a t=1 \& i d=94$ $\underline{2}$

Darwish, Abdel Nasser. (2012). Sex education for people with mental disabilities, Al Manal website. http://almanalmagazine.com Juma, Syed. (2009). Problems of Adolescents with Special Needs, Gulf Children for Special Needs website. http://www.gulfkids.com/ar/index.ph p?action $=$ show_res\& $\&$ _id $=68 \&$ topic $\_$id $=1400$

Makhzoumi, Amal. (2007). Sex education and social interaction for the mentally handicapped, Support Group website, to prevent abuse of children and women.

http://www.musanda.com , 2007, Mansour, Hamza. (2014). Awlad Berehel website: Sexual Assaults on People with Mental Disabilities The most heinous exploitation: a statement of condemnation and solidarity. http://www.hispress.info/160764.htm 1

Morsi, Muhammad. (2013). Child sexual harassment study, Al-Manal website.

http://almanalmagazine.com

Rabi ', Muhammad. (2009). the role of sex education in developing social skills for people with disabilities, website of the Bahrain Down Syndrome Association.

http://www.bdss.org/Down/main/Workshop/?id=4 57

https://www.unicef.org/ar http://www.arabvolunteering.org/corn er/avt2646.html http://www.un.org/arabic/disabilities $\angle$ default.asp?navid $=14 \&$ pid $=655$ http://www.psychiatryonline.com/reso urceTOC.aspx? resourceID=1 $\mid$ date $=$ 2000-06 